\title{
Prevalence and clinical significance of the triticeal cartilage
}

\author{
Rabia Koca $^{1}$ (D) , Zeliha Fazlığulları ${ }^{2}$ (D), Kazım Serhan Keleşoğlu ${ }^{3}$ (D), Mustafa Koplay ${ }^{3}$ (D), \\ Ahmet Kağan Karabulut ${ }^{2}$ \\ ${ }^{1}$ Department of Physical Therapy and Rebabilitation, School of Health Sciences, Afyonkarabisar Health Sciences University, Afyonkarabisar, Turkey \\ ${ }^{2}$ Department of Anatomy, School of Medicine, Selçuk University, Konya, Turkey \\ ${ }^{3}$ Department of Radiology, School of Medicine, Selçuk University, Konya, Turkey
}

\begin{abstract}
Objectives: The triticeal cartilage can be misidentified as an atheromatous plaque in the common carotid artery in radiological images. It is very important to correctly define these two structures and distinguish from each other. The aim of this study, therefore, was to investigate the shape, length, width and the anatomical position of the triticeal cartilage to prevent the interpretation of its presence as an atheromaous plaque or any other pathology located in the neck.
\end{abstract}

Methods: This study was performed retrospectively on 200 CT images of adult patients (age $\geq 20$ years; 128 males, 72 females). The shape, size and localization of triticeal cartilage were examined and its prevalence was determined.

Results: Triticeal cartilage was not present in 63 cases. It was present unilaterally in 42 cases and bilaterally in 95 . The cartilage was located at the C4 level most frequently. The triticeal cartilage was identified under 7 types as circle, double circle, oval, hook, ring, triangle and rod. Circle type was the most common. There was a statistically significant difference for the presence of ring type cartilage between males and females $(p<0.05)$. Although the mean cartilage length and width were higher in males than females, this difference was not statistically significant $(p>0.05)$.

Conclusion: The presence of the triticeal cartilage should be considered in the diagnosis of atheroma in carotid arteries. In order to distinguish the triticeal cartilage from other surrounding structures, the shape, level and size of the cartilage must be known.

Keywords: computerized tomography; thyrohyoid ligament; triticeal cartilage

Anatomy 2020;14(2):97-101 @2020 Turkish Society of Anatomy and Clinical Anatomy (TSACA)

\section{Introduction}

Triticeal cartilage is part of the complex structures in larynx. ${ }^{[1]}$ The word triticea comes from the Latin word triticeous, which resembles wheat germ. ${ }^{[2,3]}$ Triticeal cartilage is a small oval cartilage in the lateral thyrohyoid ligament between the greater horn of the hyoid bone and the superior horn of thyroid cartilage. ${ }^{[4]}$ Triticeal cartilage is found at the level of the third and fourth cervical vertebrae (C3-C4). ${ }^{[5]}$

Calcification of triticeal cartilage is associated with calcification of the thyroid cartilage. Calcification begins at the age of 20 and ends at the age of 61. Although the triticeal cartilage has been known to have no important function, it has been stated that it can help supporting lateral thyrohyoid ligament. ${ }^{[5]}$ It is also stated that calcified triticeal cartilage can be mixed with arterial plaques located in this region, particularly in common carotid artery during evaluation of radiological images such as panoramic radiography and computed tomography. It is important for clinicians to recognize the cartilage and to distinguish it from any other pathologies of the neck, other laryngeal cartilages and calcified carotid artery atheroma. ${ }^{[4]}$ Moreover, it is also important for forensic scientist to dis-

This study was an oral presentation at the 19th National Anatomy Congress \& 1st International Mediterranean Anatomy Congress/IMAC, 6-9 September 2018, Konya, Turkey. 
tinguish a calcified triticeal cartilage from the fractures of the superior horn of thyroid cartilage. ${ }^{[3,6,7]}$

The aim of this study, therefore, was to investigate the shape, length, width and the anatomical position of triticeal cartilage to prevent interpretation of its presence as an atheromaous plaque or any other pathologies in the neck.

\section{Materials and Methods}

This study was conducted with the ethical approval given by the Selçuk University School of Medicine NonInterventional Clinical Research Ethics Committee (approval number: 2018/104).

CT images of 221 patients (128 males, 72 females) were retrospectively examined between 2010-2019. These patients had undergone CT imaging because of various reasons. Out of 221 patients, 21 ( 14 males, 7 females) were either under 20 years of age (their calcification was not completed) or had a previous surgery or a pathological formation in the neck, so their CT images were excluded from the study. Thus, CT images of 200 patients who are more 20 years of age without any previous history of surgery, trauma or any kind of pathology in the neck were included to the study. The shape and size of triticeal cartilage were examined, its prevalence and possible locations was determined. The images of the patients were obtained with a 256-section $(128 \times 2)$ dual source CT (Somatom Definition Flash, Siemens, Germany) device.

The shape of the triticeal cartilage was determined under 7 different types as circle, double circles, oval, hook, ring, triangle, and rod. The shape of the cartilage was identified in sagittal sections (Figure 1). The length and width of triticeal cartilage were measured in sagittal and coronal sections. The longest distance between the superi- or and the inferior tips of the cartilage is considered as the length and the widest distance between the sides of the cartilage is considered as the width (Figure 2). The statistic of our study has been prepared in the 3.2.3 version of the R statistical software.

\section{Results}

Triticeal cartilage was not present in 63 out of 200 patients (31.5\%). Of 137 patients possessing the cartilage, 41 (20.5\%) were females and 96 (48\%) were males. The cartilage was present unilaterally in 17 females $(8.5 \%)$, and bilaterally in 24 females (12\%); unilaterally in 25 males $(12.5 \%)$ and bilaterally in 71 males (35.5\%). Accordingly, the shape, size, anatomical localization and prevalence of a total of 232 triticeal cartilages were examined (65 in females, 167 in males) (Table 1).

The triticeal cartilage was determined under 7 different types: circle, oval, hook, ring, triangle, double circle and rod. The circle type was the most common (56.5\%), rod type was the rarest $(1.3 \%)$. The circle type was present in $54.49 \%$ of males and $61.54 \%$ of females (Table 2). The ring type was significantly more common in males than females $(p<0.05)$, whereas the other types showed no statistically significant difference among genders $(p>0.05)$.

Table 1

Distribution of cases by side and gender.

\begin{tabular}{lcccc} 
& Right & Left & Bilateral & Non-calcified \\
\hline Females & 8 & 9 & 24 & 30 \\
\hline Males & 12 & 13 & 71 & 33 \\
\hline Total & 20 & 22 & 95 & 63 \\
\hline
\end{tabular}
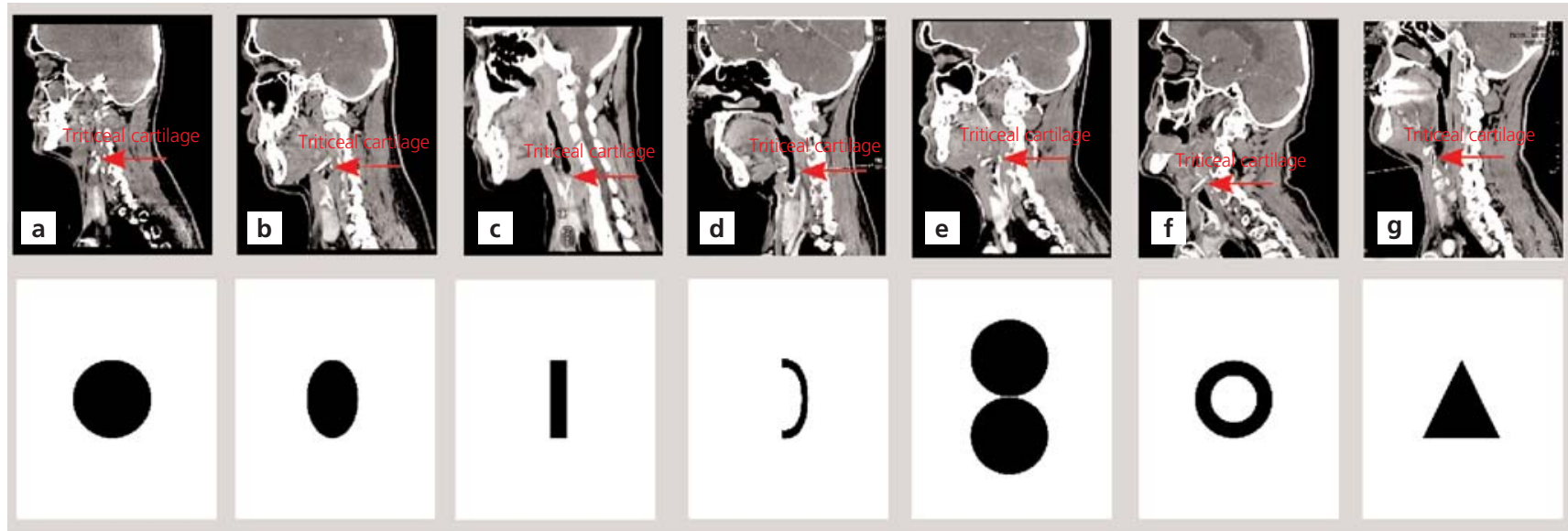

Figure 1. Determination of the shape of triticeal cartilages on sagittal CT images. (a) circle; (b) oval; (c) rod; (d) hook; (e) double circle; (f) ring; (g) triangle shaped triticeal cartilages. 
The significance of differences between the genders in terms of frequency of the type was examined by applying Z-test. In some cases, Fisher's exact test was applied, predicting that the $Z$-test may not give accurate results because the expected value is below 5 (Table 2 ).

The cartilage was located at the $\mathrm{C} 2-3$ level as the highest position and at the C6 level as the lowest. Cartilage is found most frequently at C4 level (105 cases), while the least at $\mathrm{C} 2-3$ level (4 cases).

All the cartilages were positioned between $\mathrm{C} 2-\mathrm{C} 3$ and C6 vertebrae levels. In 105 of the cases (45.3\%) it was located at the $\mathrm{C} 4$ level, being the most frequent position for both sexes ( $47.7 \%$ in females; $44.3 \%$ in males). In 4 of the cases $(1.7 \%)$ it was located at $\mathrm{C} 2-\mathrm{C} 3$ level, being the rarest position. There was no significant difference between the localization of the cartilage and gender ( $>0.05)$. The position of the cartilage showed no statistically significant difference among genders by Z-test. In some instances, Fisher's exact test was applied, predicting that the Z-test may not give accurate results because the expected value is below 5 (Table 3 ).

The mean length of the cartilage was $0.47 \pm 0.20$ (range: $0.16-1.26) \mathrm{cm}$. The mean width of the cartilage was $0.34 \pm 0.13$ (range: $0.13-0.66) \mathrm{cm}$. The mean length and width in males was $0.48 \pm 0.18$ and $0.35 \mathrm{~cm} \pm 0.11 \mathrm{~cm}$ respectively. The mean length and width in females was $0.45 \pm 0.24 \mathrm{~cm}$ respectively. Although the average cartilage length and width were higher in males, the difference was not statistically significant ( $\mathrm{p}>0.05)$ (Table 4).

\section{Discussion}

This study was based on determination of the size, shape, localization and the prevalence of triticeal cartilage on CT images. Similar studies which were per-
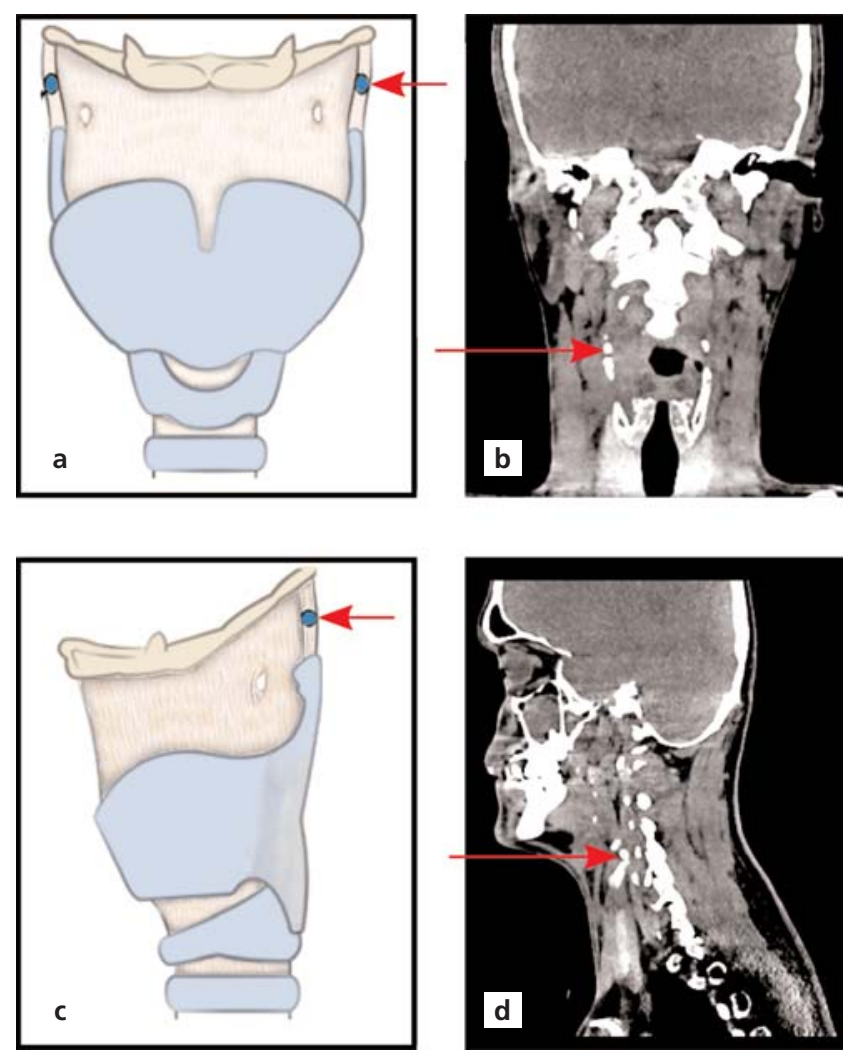

Figure 2. Triticeal cartilage on coronal and sagittal CT images. (a) illustration of triticeal cartilage on coronal plane; $(\mathbf{b})$ triticeal cartilage on a coronal CT section; (c) illustration of triticeal cartilage on sagittal plane by (d) triticeal cartilage on the sagittal section in CT.

formed on cadavers, panoramic radiographic and/or CT images revealed the localization of the cartilage at the level of the C3-C4 vertebrae. ${ }^{[1,3,4,5,8,9]}$ The triticeal cartilage was found most frequently at $\mathrm{C} 4$ level in our study (Table 3).

Table 2

Types of triticeal cartilage by shape and gender.

\begin{tabular}{|c|c|c|c|c|c|c|c|c|}
\hline \multirow[b]{2}{*}{ Type } & \multicolumn{2}{|c|}{ Total } & \multicolumn{2}{|c|}{ Males } & \multicolumn{2}{|c|}{ Females } & \multirow{2}{*}{$\begin{array}{c}\text { Z-test } \\
\text { p-value }\end{array}$} & \multirow{2}{*}{$\begin{array}{c}\text { Fisher's exact test } \\
\text { p-value }\end{array}$} \\
\hline & $n$ & Ratio (\%) & $n$ & Ratio (\%) & $\mathrm{n}$ & Ratio (\%) & & \\
\hline Rod & 3 & 1.29 & 1 & 0.6 & 2 & 3.08 & 0.20 & 0.19 \\
\hline Ring & 12 & 5.17 & 12 & 7.19 & 0 & 0 & 0.03 & 0.02 \\
\hline Hook & 5 & 2.16 & 2 & 1.2 & 3 & 4.62 & 0.13 & 0.14 \\
\hline Oval & 71 & 30.6 & 52 & 31.14 & 19 & 29.23 & 0.45 & 0.45 \\
\hline Triangle & 6 & 2.59 & 5 & 2.99 & 1 & 1.54 & 0.43 & 0.46 \\
\hline Double circle & 4 & 1.72 & 4 & 2.4 & 0 & 0 & 0.24 & 0.27 \\
\hline Circle & 131 & 56.47 & 91 & 54.49 & 40 & 61.54 & 0.20 & 0.21 \\
\hline Total & 232 & & 167 & & 65 & & & \\
\hline
\end{tabular}

$\mathrm{n}$ : number of the cases. 
Table 3

Anatomical localization of triticeal cartilage by gender.

\begin{tabular}{|c|c|c|c|c|c|c|c|c|}
\hline \multirow[b]{2}{*}{ Anatomical level } & \multicolumn{2}{|c|}{ Total } & \multicolumn{2}{|c|}{ Males } & \multicolumn{2}{|c|}{ Females } & \multirow{2}{*}{$\begin{array}{l}\text { Z-test } \\
\text { p-value }\end{array}$} & \multirow{2}{*}{$\begin{array}{c}\text { Fisher's exact test } \\
\text { p-value }\end{array}$} \\
\hline & $\mathrm{n}$ & Ratio (\%) & $\mathrm{n}$ & Ratio (\%) & $\mathrm{n}$ & Ratio (\%) & & \\
\hline$C 2-C 3$ & 4 & 1.72 & 2 & 1.2 & 2 & 3.08 & 0.34 & 0.31 \\
\hline C3 & 22 & 9.48 & 15 & 8.98 & 7 & 10.77 & 0.43 & 0.42 \\
\hline C3-C4 & 25 & 10.78 & 19 & 11.3 & 6 & 9.23 & 0.40 & 0.42 \\
\hline C4 & 105 & 45.26 & 74 & 44.31 & 31 & 47.69 & 0.38 & 0.37 \\
\hline $\mathrm{C} 4-\mathrm{C} 5$ & 24 & 10.34 & 19 & 11.38 & 5 & 7.69 & 0.28 & 0.29 \\
\hline C5 & 39 & 16.81 & 27 & 16.17 & 12 & 18.46 & 0.41 & 0.40 \\
\hline $\mathrm{C} 5-\mathrm{C} 6$ & 7 & 3.02 & 7 & 4.19 & 0 & 0 & 0.11 & 0.10 \\
\hline C6 & 6 & 2.59 & 4 & 2.4 & 2 & 3.08 & 0.5 & 0.54 \\
\hline Total & 232 & & 167 & & 65 & & & \\
\hline
\end{tabular}

$\mathrm{n}$ : number of the cases.

Calcification of the triticeal cartilage is associated with calcification of thyroid cartilage. The calcification process starts at the age of 20 and ends at the age of $61 .{ }^{[5]}$ We conducted this retrospective study on 200 CT images of patients older than 20 years old. We suggest that the present study have an important place among other studies published on this subject with the number of cases included in our study (Table 5). Our study revealed that triticeal cartilage can also be found unilaterally as it was the case in 42 patients. But its bilateral presence was more prominent being in 95 cases. Out of the 232 cartilages examined, 63 were not been calcified (Table 1).

Triticeal cartilage is a small oval cartilage ${ }^{[10]}$ Clinically, it does not have a known significant function. However, it has been stated that it can help supporting the lateral thyrohyoid ligament which is located between the hyoid bone and the superior horn of thyroid cartilage..$^{[5]}$ Triticeal cartilage was reported to be oval in shape by some previous
Table 4

Distribution of cases by size and gender.

\begin{tabular}{|c|c|c|c|c|}
\hline & Total & Male & Female & Z-test \\
\hline & Mean \pm SD $(\mathrm{cm})$ & Mean \pm SD $(\mathrm{cm})$ & Mean \pm SD $(\mathrm{cm})$ & p-value \\
\hline Length & $0.47 \pm 0.2$ & $0.48 \pm 0.18$ & $0.45 \pm 0.24$ & 0.26 \\
\hline Width & $0.34 \pm 0.13$ & $0.35 \pm 0.11$ & $0.33 \pm 0.18$ & 0.30 \\
\hline
\end{tabular}

studies in the literature. ${ }^{[1,3,6]}$ However in our study, circle shaped cartilage was the most common (56.5\%).

Radiological studies reveals that calcified triticeal cartilage can interfere with arterial plaques located in the common carotid artery. ${ }^{[3,6]}$ Fractures of the superior corn of thyroid cartilage can also be confused with triticeal cartilage and is important for forensic medicine..$^{[3,6,7]}$

Vatansever et al., ${ }^{[6]}$ found the mean length of the triticeal cartilage in males as $5.35 \mathrm{~mm}$ and in females as 4.09 $\mathrm{mm}$. In addition to this, the width was found as $3.42 \mathrm{~mm}$

Table 5

Prevalence of triticeal cartilage in previously published studies.

\begin{tabular}{|c|c|c|c|c|c|}
\hline & Unilateral & Bilateral & Non-calcified & Total & Method \\
\hline Ahmad et al. ${ }^{[3]}(2005)$ & - & - & - & 847 & Panoramic radiography \\
\hline Tubbs et al...$^{[10]}(2010)$ & - & - & - & 86 & Cadaver \\
\hline Ara et al.. ${ }^{[11]}(2012)$ & 35 & 25 & 60 & - & Autopsy \\
\hline Joshi et al. ${ }^{[1]}(2014)$ & 9 & 20 & 21 & 50 & Cadaver \\
\hline Syed $^{[5]}(2014)$ & 40 & 63 & 277 & 380 & $\begin{array}{l}\text { CBCT (Cone beam } \\
\text { computed tomography) }\end{array}$ \\
\hline Wilson et al. ${ }^{[4]}(2017)$ & 16 & 12 & 58 & 86 & Cadaver \\
\hline Alqahtani et al..$^{[12]}(2017)$ & 130 & 222 & 311 & 663 & $\mathrm{CT}$ \\
\hline Vatansever et al|. ${ }^{(6)}(2018)$ & 167 & 341 & 238 & 746 & $\mathrm{CT}$ \\
\hline Our study & 42 & 95 & 63 & 232 & CT \\
\hline
\end{tabular}


in males and $2.85 \mathrm{~mm}$ in females. ${ }^{[6]}$ In study by Joshi et al. ${ }^{[1]}$ the length of the cartilage ranged between 3.37 to 13.94 $\mathrm{mm}$ and width ranged between 2.4 to $4.79 \mathrm{~mm}$. The results of our study revealed the mean length of the cartilage as 0.47 (range: $0.16-1.26$ ) $\mathrm{cm}$, and mean width as 0.34 (range: $0.13-0.66) \mathrm{cm}$. The results of our study is similar to the studies in the literature regarding the mean values.

\section{Conclusion}

The prevalence of the triticeal cartilage is not rare. The presence and the calcification of the triticeal cartilages should be considered in order to distinguish it from other laryngeal cartilages and neck pathologies such as carotid artery atheroma or fractures in the superior horn of the thyroid cartilage. In order to distinguish this cartilage from other surrounding structures and the aforementioned pathologies, the shape, localization and the size of the cartilage should be known and should not be overlooked.

\section{Conflict of Interest}

No conflicts declared.

\section{Author Contributions}

RK: project development, data collection, data processing, manuscript writing; ZF: project development, data processing, analysis and interpretation, manuscript editing; KSK: data processing and analysis; MK: data collection; AKK: manuscript editing.

\section{Ethics Approval}

This study was approved by the Selçuk University School of Medicine Non-Interventional Clinical Research Ethics Committee (approval date and number: 2018/104).

\section{Funding Statement}

This research did not receive any specific grant from funding agencies in the public, commercial, or not-forprofit sectors.

ORCID ID:

R. Koca 0000-0002-9052-3002; Z. Fazlığulları 0000-0002-5103-090X; K. S. Keleşoğlu 0000-0001-6745-6828; M. Koplay 0000-0001-7513-4968; A. K. Karabulut 0000-0002-9635-8829

\section{References}

1. Joshi MM, Joshi SD, Joshi SS. Prevalence and variations of cartilago triticea. International Journal of Anatomy and Research 2014; 2:474-7.

2. Carter LC. Discrimination between calcified triticeous cartilage and calcified carotid atheroma on panoramic radiography. Oral Surg Oral Med Oral Pathol Oral Radiol Endod 2000;90:108-10.

3. Ahmad M, Madden R, Perez L. Triticeous cartilage: prevalence on panoramic radiographs and diagnostic criteria. Oral Surg Oral Med Oral Pathol Oral Radiol Endod 2005;99:225-30.

4. Wilson I, Stevens J, Gnananandan J, Nabeebaccus A, Sandison A, Hunter A. Triticeal cartilage: the forgotten cartilage. Surg Radiol Anat 2017;39:1135-41.

5. Syed AZ. Prevalence of carotid atheroma and its confounders on cone beam computed tomography. A dissertation submitted to the faculty of the University of North Carolina at Chapel Hill in partial fulfillment of the requirements for the Master of Science in Oral and Maxillofacial Radiology in the Department of Diagnostic Sciences at the School of Dentist. 2014; Chapel Hill. [Internet]. [Retrieved on June 10, 2020]. Available from: file:///C:/Users/ user/Downloads/6105.pdf

6. Vatansever A, Demiryürek D, Tatar İ, Özgen B. The triticeous cartilage-redefining of morphology, prevalence and function. Folia Morphol (Warsz) 2018;77:758-63.

7. Di Nunno N, Lombardo S, Costantinides F, Di Nunno C. Anomalies and alterations of the hyoid-larynx complex in forensic radiographic studies. Am J Forensic Med Pathol 2004;25:14-19.

8. Cohen SN, Friedlander AH, Jolly DA, Date L. Carotid calcification on panoramic radiographs: An important marker for vascular risks. Oral Surg Oral Med Oral Pathol Oral Radiol Endod 2002; 94:510- 4 .

9. Mesa Marrero M, Villarreal Salcedo M. Symptomatic presentation of calcified triticeal cartilage. [Article in Spanish] Acta Otorrinolaringol Esp 2009;60:75-6.

10. Tubbs RS, Dixon JF, Loukas M, Shoja MM, Cohen-Gadol AA. Relationship between the internal laryngeal nerve and the triticeal cartilage: a potentially unrecognized compression site during anterior cervical spine and carotid endarterectomy operations. Neurosurgery 2010;66(6 Suppl Operative):187-90.

11. Ara A, Rahman MM, Ara ZG, Chowdhury Al, Begüm T, Chowdhury MR, Fazilatunnesa. The incidence of cartilago triticea in Bangladeshi cadaver. Community Based Medical Journal 2012;1:8-10.

12. Alqahtani E, Marrero DE, Champion WL, Alawaji A, Kousoubris PD, Small JE. Triticeous cartilage CT imaging characteristics, prevalence, extent, and distribution of ossification. Otolaryngol Head Neck Surg 2016;154:131-7.

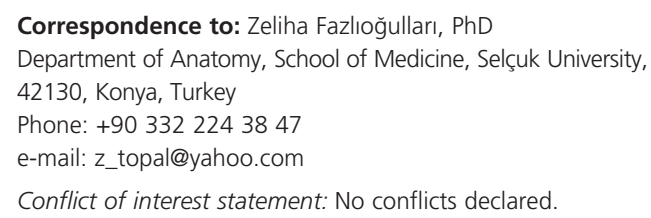

Conflict of interest statement: No conflicts declared.

This is an open access article distributed under the terms of the Creative Commons Attribution-NonCommercial-NoDerivs 4.0 Unported (CC BY-NCND4.0) Licence (http://creativecommons.org/licenses/by-nc-nd/4.0/) which permits unrestricted noncommercial use, distribution, and reproduction in any medium, provided the original work is properly cited. How to cite this article: Koca R, Fazlığulları Z, Keleşoğlu KS, Koplay M, Karabulut AK. Prevalence and clinical significance of the triticeal cartilage. Anatomy 2020;14(2):97-101. 